\title{
Acute coronary syndrome: factors predicting smoking cessation
}

Hela Abroug, ${ }^{1}$ Aymen El Hraiech, ${ }^{2}$ Ons Mehrez, ${ }^{3}$ Manel Ben Fredj, ${ }^{1}$ Imen Zemni, ${ }^{1}$ Arwa Ben Salah, ${ }^{1}$ Mohamed Azaiez, ${ }^{2}$ Walid Jomaa, ${ }^{2}$ Faouzi Maatouk ${ }^{2}$ and Asma Belguith ${ }^{1}$

${ }^{1}$ Department of Epidemiology and Preventive Medicine, University Hospital of Monastir, Tunisia. ${ }^{2}$ Department of Cardiology, Fattouma Bourguiba Hospital, Monastir, Tunisia. ${ }^{3}$ Department of Family Medicine Faculty of Medicine, University Hospital of Monastir, Tunisia. (Correspondence to: Asma S. Belguith: belguith_asma@yahoo.fr).

\begin{abstract}
Background: Few randomized controlled trials have examined the efficacy time of smoking cessation in hospitalized patients with acute coronary syndrome, either during hospitalization or after discharge.

Aims: To assess smoking cessation rates at 24 weeks among patients with acute coronary syndrome. Group A had begun nicotine replacement therapy during hospitalization, and Group B after discharge. We also determined factors predicting success.

Methods: We conducted a randomized controlled trial in the Cardiology Department and Smoking Cessation Service at University Hospital of Monastir, Tunisia from January 2015 to June 2016. Participants were randomly assigned to the above 2 groups. The endpoint assessment was smoking abstinence at 24 weeks, defined as self-reported abstinence in the past week, confirmed by measured exhaled carbon monoxide $(\mathrm{CO}) \leq 8 \mathrm{ppm}$. We analysed data by intention to treat. We used a binary logistic regression model to determine factors predicting abstinence.
\end{abstract}

Results: All participants were male and mean (standard deviation) age was 55 (11) years. At 24 weeks there was no significant difference in smoking cessation rate between the 2 groups: $54.5 \%$ [95\% confidence interval (CI): 44.7-64.3\%] in Group A and $45.5 \%(95 \%$ CI: $35.7-55.3 \%)$ in Group B $(P=0.81)$. High level of nicotine dependence [odds ratio (OR): $0.72 ; 95 \%$ CI: 0.54-0.96) and good compliance during follow-up (OR: 6.56; 95\% CI: 2.07-20.78) were predictive factors for abstinence.

Conclusions: Smoking cessation rate after acute coronary syndrome was high regardless of the start date. Good compliance during follow-up was the key predictive factor for success.

Keywords: acute coronary syndrome, clinical trial, predictive factors, smoking cessation, Tunisia

Citation: Abroug H; El Hraiech A; Mehrez O; Ben Fredj M; Zemni I; Ben Salah A et al. Acute coronary syndrome: factors predicting smoking cessation. East Mediterr Health J. 2020;26(3):312-319. https://doi.org/10.26719/emhj.19.034

Received: 23/11/17; accepted: 05/07/18

Copyright (c) World Health Organization (WHO) 2020. Open Access. Some rights reserved. This work is available under the CC BY-NC-SA 3.o IGO license (https://creativecommons.org/licenses/by-nc-sa/3.o/igo).

\section{Introduction}

Smoking is the main preventable cause of morbidity and premature death worldwide (1) and is a major and independent risk factor for coronary heart disease (CHD) (2). More than two thirds of sudden cardiac death resulting from acute thrombus occurs in smokers (3). Compared to nonsmokers the odds ratio (OR) for myocardial infarction is $\sim 2.5$, and for cardiovascular diseases overall the OR is $\sim 2$ $(2,4)$. Smoking cessation in persons with known CHD reduces the risk of recurrent myocardial infarction or cardiovascular death from 30 to $50 \%$ (5) during the subsequent 3-7 years (6). Nevertheless, although smoking cessation is potentially the most effective CHD prevention strategy, quitting smoking is difficult and two thirds of patients return to smoking within 1 year of their acute coronary syndrome $(\operatorname{ACS})(7,8)$. Therefore, being hospitalized for a major cardiac condition, such as ACS, can be an opportunity to prompt many individuals to stop smoking.

Exploitation of this opportunity immediately after ACS may make it possible to increase smoking abstinence in this high-risk population (8). Cessation rates among smokers hospitalized for ACS range from 31\% without intervention to $60 \%$ with sustained intervention after hospitalization at 1-year follow-up (9). Nicotine replacement therapy (NRT), bupropion and varenicline, compared to placebo, have demonstrated efficacy for smoking cessation, yet most smokers consider smoking to be a voluntary behaviour and declined to be treated. Currently, smoking cessation remains a secondary concern in cardiology departments and there are few strategies offered to smokers with established CHD.

NRT improves smoking cessation rates without major adverse events (1), with equal rates of cessation in the general population and patients with CHD, as well as improving clinical outcomes among CHD patients (10). Many studies have examined the benefits of smoking cessation after ACS and the efficacy of smoking cessation pharmacotherapy in hospitalized patients with ACS. However, few randomized controlled trials have examined the efficacy time of smoking cessation in hospitalized patients with ACS either during hospitalization or after discharge. We compared among patients with ACS smoking cessation rates with NRT when begun in hospital or after discharge. 


\section{Methods}

\section{Design and study population}

A randomized controlled trial was conducted simultaneously in the Smoking Cessation Service and the Department of Cardiology at the University Hospital of Monastir, Tunisia. The study was performed from January 2015 to June 2016 with a mean 24 weeks of run-up and 24 weeks of follow-up. There were 99 patients, all male, with a mean (standard deviation) age of $55(t)$ years, range $25-81$ years. Patients were hospitalized with ACS. Patients were actively smoking at the time of inclusion, motivated to quit smoking, able to provide informed consent, and willing to participate in a clinical study including a follow-up examination every 2 weeks after hospital discharge. Active smoking was defined as smoking at least 1 cigarette (or water pipe) per day during the month preceding hospitalization. Exclusion criteria were refusal of assistance for smoking cessation, inability to attend follow-up clinical visits (professional, regional or physical hindrance), or diagnosis of depression or other serious health condition at admission (e.g., ventilatory support or cardiogenic shock).

\section{Sampling}

We hypothesized that NRT after ACS during hospitalization would improve smoking cessation rate compared to NRT after discharge. Previous studies reported a rate of $51 \%$ among smokers who received NRT for smoking cessation in hospital (11) and $32.7 \%$ among patients receiving treatment after discharge (12). An expected sample size of 68 participants was calculated with a power of 0.80 and 2 -sided $P<0.05$. The proportion of patients who dropped out or withdrew was expected to be $30 \%$. Hence, a minimum sample size of 89 was necessary, and the final sample was 99 consecutive patients.

Randomization was performed after consent was obtained (Figure 1). There were 54 patients in Group A and 45 in Group B $(P=0.366)$. Participants were randomized to Group A, who received counselling and NRT during hospital stay 1 day after SCA. Those in Group B benefited from counselling during hospital stay, but NRT was offered at a mean 14 days after SCA at the first clinical visit after discharge. All patients attended regular follow-up visits at the Smoking Cessation Service every 2 weeks. Forty-four $(81.4 \%)$ and $30(66.6 \%)$ patients completed the follow-up smoking cessation in Group A and Group B, respectively. Loss to follow-up was equal in both groups $(P=0.931)$.

\section{Study protocol and data collection}

\section{During hospitalization}

All patients in the sample received individual therapeutic education including a motivational interview. Patients were asked about their sociodemographic status, history of tobacco use, level of nicotine dependence (Fagerstrom test for nicotine dependence) (13), psychological state (using Hospital Anxiety and Depression Scale) (14), coaddiction (alcohol, drugs or cannabis), and level of motivation to quit smoking (QMAT scale). The scale consists of 4 questions whose response modalities generate a score of $0-20: \leq 6$, insufficient motivation; $6-13$, average motivation; and $>13$, very good motivation. Participants in Group A started NRT patches and gum during hospitalization. The first appointment was scheduled at 1 week after hospital discharge.

\section{After hospital discharge}

Participants in Group B started NRT patches and gum after hospital discharge. At the first clinical visit, 2 weeks after their SCA event, adverse effects, symptoms of withdrawal, medication adherence and smoking status were assessed. Smoking status was assessed by self-reporting of smoking in the preceding 7 days and confirmed by exhaled CO (ECO). The threshold of ECO was < 8 ppm. Follow-up involved clinical visits every 2 weeks and telephone calls were made to patients who missed their meeting, for whom a new consultation was organized as soon as possible.

A reduction of NRT dose by one third was required every 28 days and NRT dose was adjusted according to signs of under- or overdose. During the processing time, there was close collaboration with a team comprising a psychiatrist, addictologist and clinical psychologist to manage more complicated cases such as dual addiction, depression and type A personalities.

\section{Follow-up assessment}

The primary endpoint was 7-days smoking abstinence at 24 weeks following randomization, defined as self-reported abstinence in the past week before the 24-week clinical visit, confirmed by measured ECO $\leq 8 \mathrm{ppm}$. Participants with self-reported abstinence who had ECO > $8 \mathrm{ppm}$, or who reported any smoking in the last week and ECO $\leq 8 \mathrm{ppm}$, were classified as current smokers. Secondary endpoints included measures by face-to-face survey; compliance with medication; occurrence of adverse effects of NRT patches (e.g., allergic skin reaction) (15); withdrawal symptoms (nervousness, headache, lack of concentration, insomnia, and craving); and benefits of smoking cessation (improvement of respiratory signs, increased appetite, sleep quality, and enhanced physical activity). Compliance with treatment was defined as good if the wearing of nicotine patches was on a regular basis.

\section{Endpoint assessment}

Smoking cessation status was assessed during visits at 24 weeks. A telephone survey was performed for patients who had missed appointments.

\section{Ethical considerations}

Written and informed consent was obtained from all study participants. Participants were given the opportunity to ask questions and decide whether to participate. This trial is registered with Clinical Trials.gov, number: NCT03209622.

\section{Statistical analysis}

Statistical analyses were performed using SPSS version 19.0. The primary data analysis examined point prevalence 


\section{Figure 1 Flow diagram demonstrating follow-up of enrolled patients}

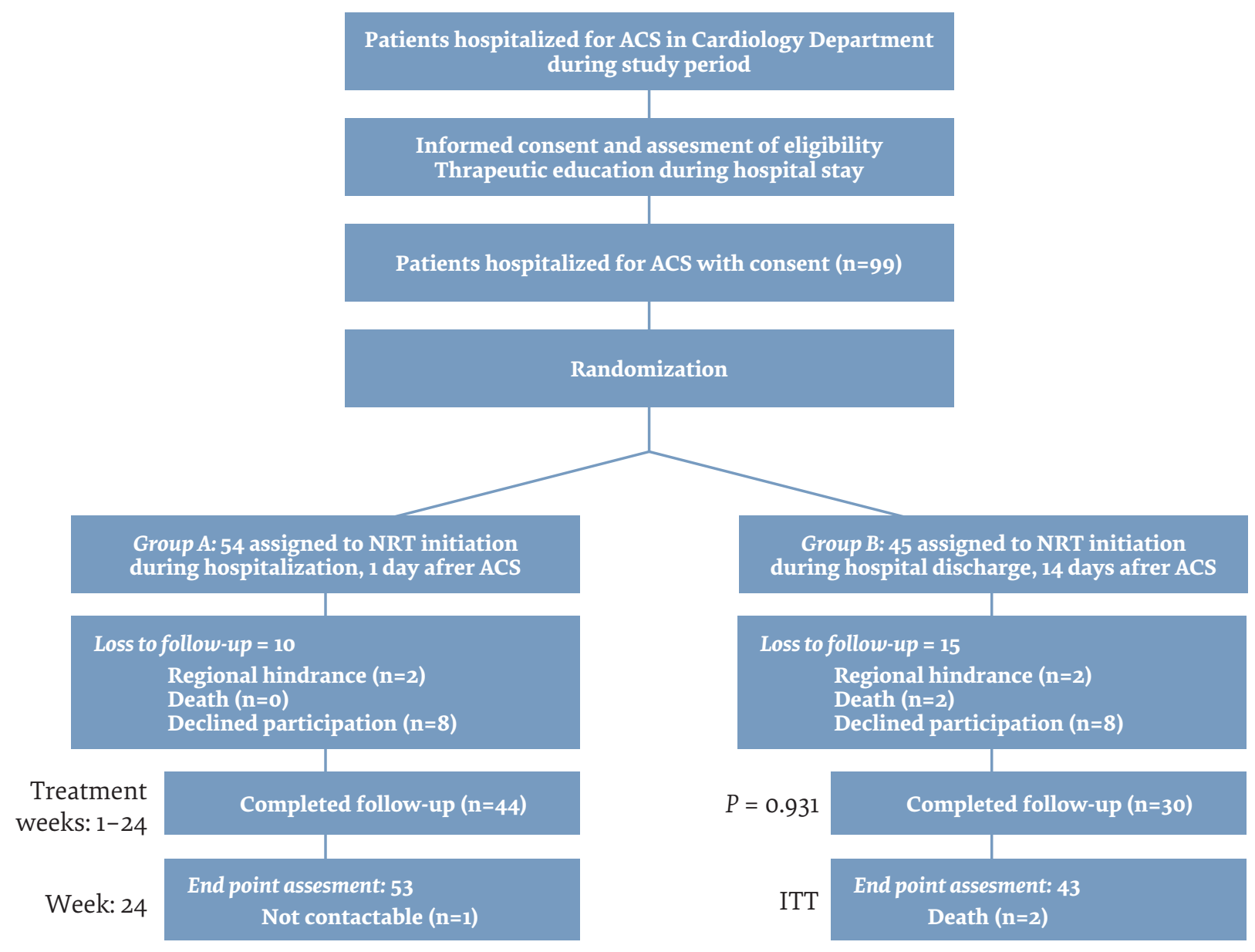

ACS = acute coronary syndrome; ITT = intention to treat; NRT = nicotine replacement therapy

smoking abstinence at 24 weeks. All analyses were intention-to-treat adjusted by ACS type [ST segment elevation myocardial infarction (STEMI) or non-STEMI (NSTEMI)]. Binary logistic regression was used to determine the factors that were independent predictors of smoking cessation success $(P<0.05)$. Variables with $P<0.2$ in the univariate analysis were included in the multivariate analysis. $P<0.05$ was considered statistically significant.

\section{Results}

\section{Patient characteristics at baseline}

At baseline, 93 patients (94\%) used cigarettes with a mean 32 (14) cigarettes per day. A high nicotine dependence was found among 49 patients. Two thirds of patients had 2 or more major cardiovascular risk factors other than smoking. Half of patients (49.5\%) had NSTEMI. The participant characteristics in the 2 groups are summarized in Table 1. Despite randomization, NSTEMI was found in 18 (37.5\%) and $31(62.5 \%)$ patients in Group A and B, respectively $(P=0.002)$. Length of stay in the cardiac intensive care unit was longer in Group B $(P=0.007)$.

\section{Smoking abstinence at 24 weeks}

Successful smoking cessation rates, with intention-to-treat analysis, were $57.1 \%$ [95\% confidence interval (CI): $39.6-74.6 \%$ in Group A and $42.9 \%$ (95\% CI: $20.8-64.9 \%$ ) in Group B. OR adjusted by length of stay in cardiac intensive care unit and SCA type was 0.824 $(0.334-2.032)(P=0.674)$.

\section{Predictors of smolking cessation success}

Factors associated for successful smoking cessation are shown in Table 2. The likelihood of success was associated with good follow-up compliance, living in a tobacco-free family environment, NSTEMI, history of diabetes and good motivation to quit. Smokers with high nicotine dependence had less chance of success.

\section{Discussion}

This study was designed to compare 2 protocols of smoking cessation immediately after ACS. There was no significant difference between initiation of smoking cessation by NRT during hospitalization or after discharge. To our knowledge, there have been no previous 


\begin{tabular}{|c|c|c|c|}
\hline Demographic variables & Group A & Group B & $\mathbf{P}$ \\
\hline Number & 54 & 45 & 0.366 \\
\hline Mean (SD) age, year & $55(11)$ & $55(10)$ & 0.76 \\
\hline \multicolumn{4}{|l|}{ Level of education, $n$ (\%) } \\
\hline Analphabet/primary & $29(53.7)$ & $18(40.0)$ & \\
\hline Secondary/university & $25(47.3)$ & $27(60.0)$ & 0.18 \\
\hline \multicolumn{4}{|l|}{ Working status, $\mathbf{n}(\%)$} \\
\hline Employed, n (\%) & $39(72.2)$ & $33(73.3)$ & 0.902 \\
\hline \multicolumn{4}{|l|}{ Smoking variables } \\
\hline Type (cigarettes), n (\%) & $51(98.1)$ & $42(89.4)$ & 0.10 \\
\hline Cigarettes per day, mean (SD) & $29.4 \pm 14.9$ & $34.3 \pm 13.3$ & 0.09 \\
\hline Prior attempt to quit: $\mathrm{n}(\%)$ & $28(51.9)$ & $21(46.7)$ & 0.607 \\
\hline Motivation score to quit (QMAT scale) mean (SD) & $19.2 \pm 2.6$ & 19.04 & 0.752 \\
\hline FTNDS, mean (SD) & $6.13(2.2)$ & $6.31(2.1)$ & 0.690 \\
\hline$\geq 7$ (severe), $\mathrm{n}(\%)$ & $25(48.1)$ & $24(53.3)$ & 0.606 \\
\hline Alcohol consumption & $11(20.4)$ & $9(20.0)$ & 0.964 \\
\hline Other household smokers & $11(20.4)$ & $9(20.0)$ & 0.964 \\
\hline Clinical characteristics & $15(28.3)$ & $14(31.1)$ & 0.761 \\
\hline Presence of CVRF other than smoking, $n$ (\%) & $20(42.6)$ & $13(26)$ & 0.17 \\
\hline Diabetes & $20(42.6)$ & $17(33.8)$ & 0.64 \\
\hline Hypertension & $16(34)$ & $13(28.9)$ & 0.59 \\
\hline Hyperlipidaemia & $21(44.7)$ & $18(40)$ & 0.65 \\
\hline Obesity (BMI $\geq 30)$ & $6(12.8)$ & $9(20.5)$ & 0.32 \\
\hline PAOD & $4(8.5)$ & $2(4.4)$ & 0.67 \\
\hline History of CVD (prior to baseline event) & $12(23.1)$ & $16(34)$ & 0.22 \\
\hline History of depression & o & o & \\
\hline \multicolumn{4}{|l|}{ Admission event, $n$ (\%) } \\
\hline STEMI & $30(68.9)$ & $14(31.1)$ & \\
\hline NSTEMI & $18(37.5)$ & $31(62.5)$ & 0.002 \\
\hline Presence of complication yes, $\mathrm{n}(\%)$ & $11(22.9)$ & $13(28.9)$ & 0.51 \\
\hline Length of stay in Cardiology Department (weeks), Median (IQR) & $8(6-11)$ & $9(7-12)$ & 0.121 \\
\hline Length of stay CICU (week), Median (IQR) & $3(0.5-4)$ & $4(3-4)$ & 0.007 \\
\hline Follow up duration (week) Median (IQR) & $24(11-31)$ & $17.5(11.25-27.5)$ & 0.250 \\
\hline \multicolumn{4}{|l|}{ Treatment, $\mathbf{n}(\%)$} \\
\hline No intervention & $11(23.9)$ & $9(20)$ & \\
\hline $\mathrm{PCI} / \mathrm{CABG}$ & $35(76.1)$ & $36(80)$ & 0.65 \\
\hline \multicolumn{4}{|l|}{ Number of clinical visits, $\boldsymbol{n}$ (\%) } \\
\hline$\geq 4$ & $16(30.1)$ & $22(46.8)$ & 0.10 \\
\hline \multicolumn{4}{|l|}{ Compliance, $n(\%)$} \\
\hline Good $^{a}$ & $24(46.2)$ & $21(44.7)$ & \\
\hline Poor $^{\mathrm{b}}$ & $28(53.8)$ & $26(55.3)$ & 0.88 \\
\hline
\end{tabular}




\begin{tabular}{|c|c|c|c|}
\hline Demographic variables & Group A & Group B & $\mathbf{P}$ \\
\hline \multicolumn{4}{|c|}{ Occurrence of adverse effects of NRT, $\boldsymbol{n}(\%)$} \\
\hline Allergic skin reaction & $2(7.1)$ & $3(10.3)$ & 1 \\
\hline \multicolumn{4}{|l|}{ Withdrawal symptoms, $n$ (\%) } \\
\hline None & $21(40.4)$ & $14(29.8)$ & \multirow{3}{*}{0.10} \\
\hline Nervousness & $5(9.6)$ & $12(25 \cdot 5)$ & \\
\hline Others $^{c}$ & $26(50)$ & $21(44.7)$ & \\
\hline \multicolumn{4}{|l|}{ Benefits of smoking cessation, $n(\%)$} \\
\hline Improvement of respiratory signs & $28(57.1)$ & $30(60)$ & \multirow{3}{*}{0.99} \\
\hline Increased appetite & $10(20.4)$ & $11(22)$ & \\
\hline Others $^{\mathrm{d}}$ & $7(14.2)$ & $8(16)$ & \\
\hline \multicolumn{4}{|l|}{${ }^{a}$ Wearing nicotine patches on a regular basis. } \\
\hline \multicolumn{4}{|l|}{${ }^{b}$ Wearing nicotine patches on an irregular basis. } \\
\hline \multicolumn{4}{|l|}{ 'Headache, lack of concentration, insomnia, craving. } \\
\hline \multicolumn{4}{|c|}{ 'Sleep quality improvement, enhancement of physical activity. } \\
\hline \multicolumn{4}{|c|}{$\begin{array}{l}B M I=\text { body mass index } ; C A D=\text { coronary artery disease } ; C A B G=\text { coronary artery bypass grafting; } C I C U=\text { cardiac intensive care unit; } C V D=\text { cardiovascular disease; } C V R F=\text { cardiovascular risk } \\
\text { factor; } F T N D S=\text { Fagerstrom test for nicotine dependence score; } N R T=\text { nicotine replacement therapy; } N S T E M I=\text { non-ST segment-elevation myocardial infarction; } P A O D=\text { peripheral arterial } \\
\text { occlusive disease; } P C I=\text { percutaneous coronary intervention; STEMI = ST segment-elevation myocardial infarction. }\end{array}$} \\
\hline
\end{tabular}

trials on smoking cessation performed in patients with ACS in Tunisia.

Patients included in our study were all male. The average age of our coronary population was close to that found in previous studies of smoking cessation in the same population (16-20). Most patients were heavy smokers. Our results were similar to those described in other studies of smoking cessation after ACS (21). These findings are encouraging for the promotion of effective awareness-raising actions for heavy smokers. During the study period, no women developed ACS related to smoking. In fact, in Tunisia, female smoking is considered a social taboo, thus limiting tobacco use in women.

Smoker psychology and ability to change behaviour were described in the Prochaska and Di Clemente model (22). After a cardiac event, the successive stages of the Prochaska cycle are "short circuited" (22) and the patients are often highly motivated to quit smoking (8). In the current study the majority of patients were already highly motivated to quit smoking and hospitalization in the Cardiology Department could be a good opportunity to initiate smoking cessation (23). Also, coronary revascularization such as angioplasty or coronary artery bypass surgery is an alarming event for patients hospitalized for ACS and increases intention to quit $(24,25)$. Previously, the safety and effectiveness of NRT for patients immediately after ACS were unclear because of potential haemodynamic effects of nicotine (26). Recently, safety and efficacy of NRT in patients with recent SCA were documented $(1,2,16,27)$ and the use of NRT to quit smoking roughly doubles the success rate in long-term abstinence by reducing withdrawal symptoms (16).
Smoking abstinence rates at 24 weeks were $54.5 \%$ in Group A and 45.5\% in Group B. Our results were equivalent to those reported in the literature, particularly in randomized controlled trials with rates ranging from 30.4 to $62 \%(7,9,10,17-20,24)$. This result could be explained by the effectiveness of a multidisciplinary management team and the intensive intervention adopted in this protocol. This finding was supported by the literature, which shows that intensive intervention is more effective (28). The difference in smoking abstinence rates from those in the literature could be explained by the pharmacotherapy used: NRT, varenicline or bupropion, with NRT being the only available treatment for smoking cessation in Tunisia. Cardiologists have to be more effective in promoting

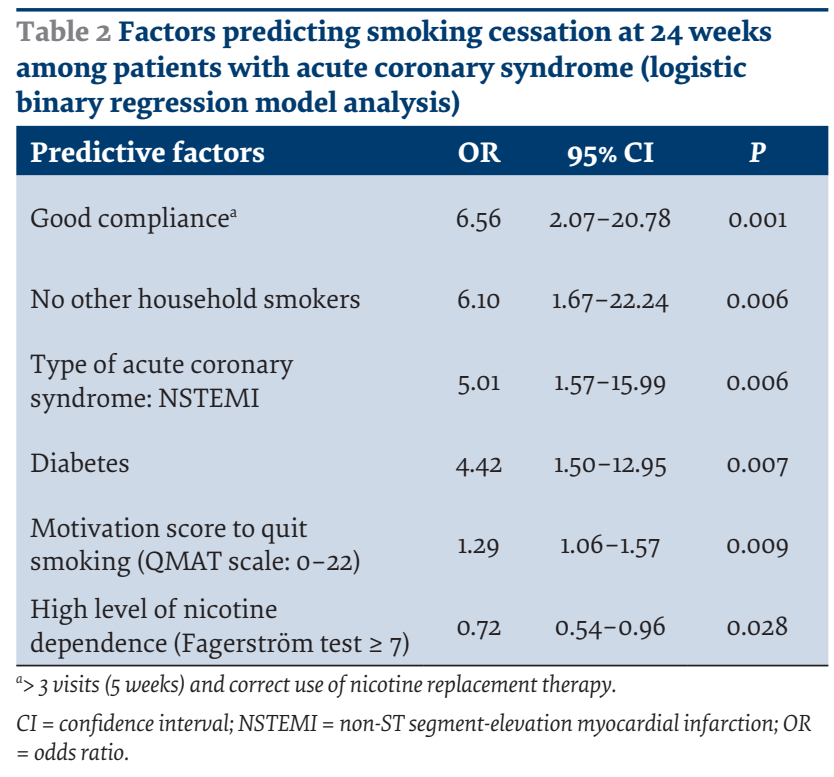


quitting motivation (29); offering brief advice and encouragement to patients is insufficient $(27,28)$ and they must start NRT as soon as possible.

According to our findings and regardless of treatment groups, patients with STEMI and no other household smokers were significantly associated with smoking cessation. Likewise, smoking cessation rate was related to good treatment compliance $(10,11,30,31)$. These results suggest that such a programme should be applied as a main part of the post-ACS routine following the recommendations of the European Society of Cardiology (32). Diabetes increased the chances of smoking cessation in our study population, which was consistent with the study of Kim et al. (33). However, the presence of other diseases such as stroke (30), previous cardiac events (5), diseases related to smoking, depression $(30,34)$ and a history of anxiolytic use (34) is significantly associated with smoking cessation failure. Concomitant with other studies, a high level of nicotine dependence was significantly associated with smoking cessation failure (30). Finally, a high motivation score to quit is a significant predictive factor for smoking cessation (35), showing that the period of hospitalization is an opportunity to help these patients.
The main limitation in our study was sample size. Also, the exclusion criteria (refusal of assistance for smoking cessation, inability to attend follow-up clinical visits, or diagnosis of depression or other serious health condition at admission) may constitute selection bias that may overestimate our results. However, the study determined the effect of early NRT after ACS. This study is continuing to determine the long-term effect of treatment.

\section{Conclusions}

At 24 weeks there were no significant differences in smoking cessation rates between initiating smoking cessation during hospitalization or after discharge. Diabetes, NSTEMI, good motivation for smoking cessation, good treatment compliance and living in a tobacco-free family environment were predictive factors for successful smoking cessation. High nicotine dependence decreased the likelihood of smoking cessation.

\section{Funding: None}

Competing interests: None declared.

\section{Syndrome coronarien aigu : facteurs prédictifs de la réussite du sevrage tabagique Résumé}

Contexte : Peu d'essais contrôlés randomisés ont examiné la durée garantissant l'efficacité du sevrage tabagique chez les patients hospitalisés atteints d'un syndrome coronarien aigu, soit pendant leur hospitalisation, soit après leur sortie.

Objectifs : Évaluer les taux de sevrage tabagique à 24 semaines chez les patients atteints d'un syndrome coronarien aigu. Les patients du groupe A avaient entamé une thérapie de substitution nicotinique lors de leur hospitalisation, et ceux du groupe $B$, après leur sortie. Nous avons aussi déterminé les facteurs prédictifs de la réussite du sevrage.

Méthodes : Nous avons mené un essai contrôlé randomisé dans le département de cardiologie et le service de sevrage tabagique de l'hôpital universitaire de Monastir, en Tunisie, de janvier 2015 à juin 2016. Les participants ont été répartis dans les deux groupes susmentionnés de manière aléatoire. Le critère d'évaluation final était le sevrage tabagique à 24 semaines, défini comme l'abstinence auto-déclarée au cours de la semaine écoulée, confirmé par la mesure du monoxyde de carbone expiré (inférieur ou égal à $8 \mathrm{ppm}$ ). Nous avons effectué une analyse en intention de traiter sur les données. Un modèle de régression logistique binaire a été employé pour déterminer les facteurs prédictifs de l'abstinence.

Résultats : Tous les participants étaient de sexe masculin, pour un âge moyen (écart type) de 55 (11) ans. À 24 semaines, on ne notait pas de différence significative dans le taux de sevrage tabagique des deux groupes : 54,5\% (intervalle de confiance à $95 \%$ [IC] : 44,7-64,3\%) dans le groupe A et 45,5\% (IC à 95\%:35,7-55,3\%) dans le groupe B ( $p=0,81)$. Un niveau élevé de dépendance nicotinique [odds ratio (OR) : 0,72 ; IC à $95 \%$ : 0,54-0,96) et une bonne observance en phase de suivi (OR : 6,56 ; IC à $95 \%$ : 2,07-20,78) étaient des facteurs prédictifs de l'abstinence.

Conclusions : Le taux de sevrage tabagique suivant un syndrome coronarien aigu était élevé, indépendamment de la date de début d'abstinence. Une bonne observance en phase de suivi était le facteur prédictif clé pour la réussite du sevrage.

$$
\begin{aligned}
& \text { المتلازمة التاجية الحادة: العوامل التي تُنبئ بالإقلاع عن التدخين }
\end{aligned}
$$

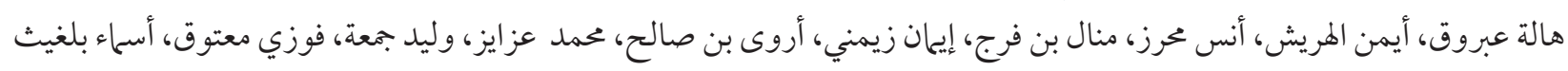

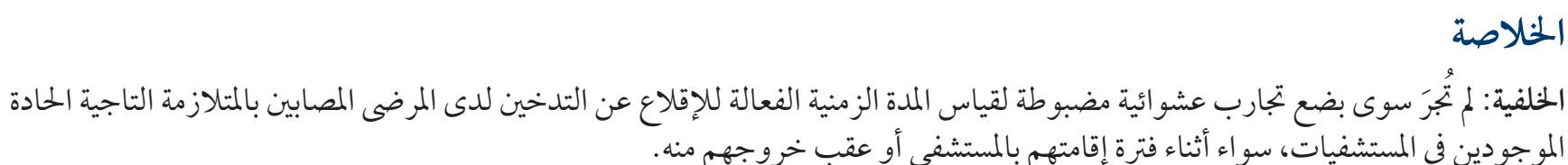

$$
\begin{aligned}
& \text { الأهداف: هدفت الدراسة إلى تقييم معدلات الإقلاع عن التدخين في الأسبوع ع ب بين المرضى المصابين بالمتلازمة التاجية الحادة. وقد بدأ أفراد }
\end{aligned}
$$


المجموعة أ العلاج ببدائل النيكوتين أثناء فترة إقامتهم بالمستشفى، بينما بدأ أفراد المجموعة ب العلاج عقب خروجهم من المستشفى. كذلك حددنا العوامل التي تنبئ بإحراز النجاح.

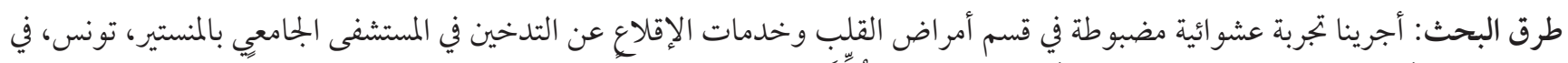

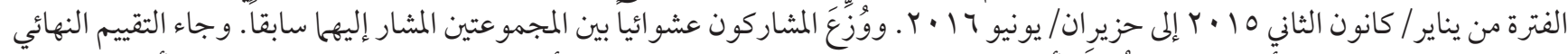

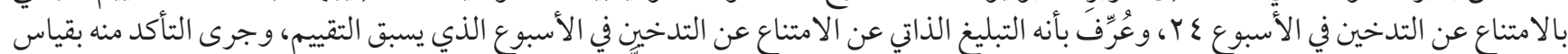

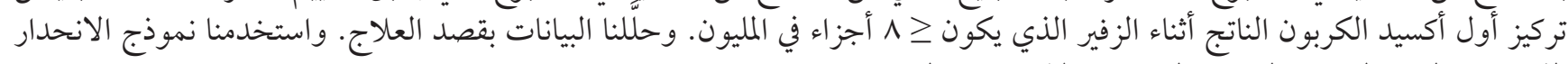
اللوجستي الثنائي لتحديد العوامل التي تنبئ بالامتناع عن التئ التدخين.

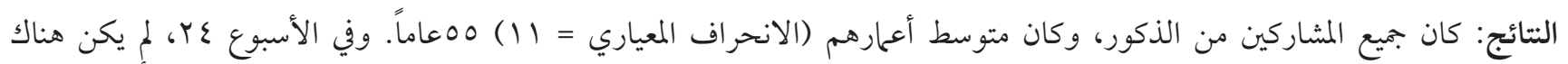

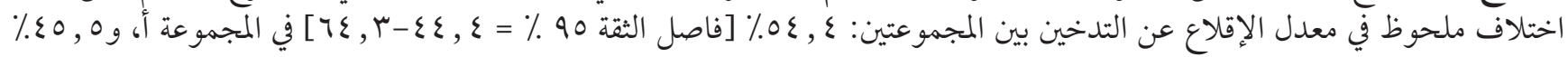

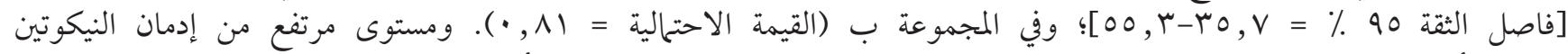

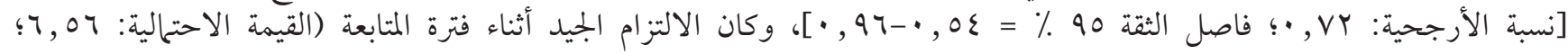

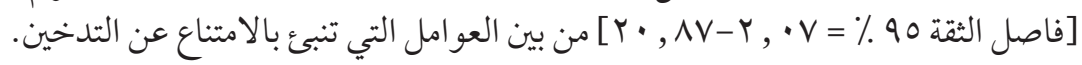

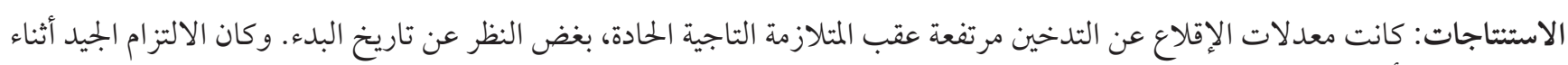
فترة المتابعة هو أهم العوامل التي تنبئ بالنجاح.

\section{References}

1. Cahill K, Lindson-Hawley N, Thomas KH, Fanshawe TR, Lancaster T. Nicotine receptor partial agonists for smoking cessation. Cochrane Database Syst Rev. 2016 May 9;9:CDo06103. http://dx.doi.org/10.1002/14651858.CDoo6103 PMID:27158893

2. Barth J, Jacob T, Daha I, Critchley JA. Psychosocial interventions for smoking cessation in patients with coronary heart disease. Cochrane Database Syst Rev. 2015 Jul 6;6:CDoo6886. http://dx.doi.org/10.1002/14651858.CDoo6886 PMID:26148115

3. Yahagi K, Joner M, Virmani R. Impact of smoking on coronary heart disease: is there a smoker's paradox? Coron Artery Dis. 2015 Sep;26(6):466-8. http://dx.doi.org/10.1097/MCA.0000000000000274 PMID:26217891

4. Baccouche H, Belguith AS, Boubaker H, Grissa MH, Bouida W, Beltaief K, et al. Acute coronary syndrome among patients with chest pain: prevalence, incidence and risk factors. Int J Cardiol. 2016 Jul 1;214:531-5. http://dx.doi.org/10.1016/j.ijcard.2015.11.065 PMID:26586217

5. Snaterse M, Scholte op Reimer WJM, Dobber J, Minneboo M, ter Riet G, Jorstad HT, et al. Smoking cessation after an acute coronary syndrome: immediate quitters are successful quitters. Neth Heart J. 2015 Dec;23(12):600-7. http://dx.doi.org/10.1007/ S12471-015-0755-9 PMID:26449241

6. Chow CK, Jolly S, Rao-Melacini P, Fox KAA, Anand SS, Yusuf S. Association of diet, exercise, and smoking modification with risk of early cardiovascular events after acute coronary syndromes. Circulation. 2010 Feb 16;121(6):750-8. http://dx.doi.org/10.4081/ monaldi.2010.280 PMID:20124123

7. Windle SB, Bata I, Madan M, Abramson BL, Eisenberg MJ. A randomized controlled trial of the efficacy and safety of varenicline for smoking cessation after acute coronary syndrome: design and methods of the Evaluation of Varenicline in Smoking Cessation for Patients Post-Acute Coronary Syndrome trial. Am Heart J. 2015 Oct;170(4):635-40. http://dx.doi.org/10.1016/j. ahj.2015.07.010 PMID:26386786

8. Eisenberg MJ, Grandi SM, Gervais A, O’Loughlin J, Paradis G, Rinfret S, et al. Bupropion for smoking cessation in patients hospitalized with acute myocardial infarction: a randomized, placebo-controlled trial. J Am Coll Cardiol. 2013 Feb 5;61(5):524-32. http:// dx.doi.org/10.1016/j.jacc.2012.08.1030 PMID:23369417

9. Holtrop JS, Stommel M, Corser W, Holmes-Rovner M. Predictors of smoking cessation and relapse after hospitalization for acute coronary syndrome. J Hosp Med. 2009 Mar;4(3):E3-9. http://dx.doi.org/10.1002/jhm.415 PMID:19301384

10. Grandi SM, Eisenberg MJ, Joseph L, O’Loughlin J, Paradis G, Filion KB. Cessation treatment adherence and smoking abstinence in patients after acute myocardial infarction. Am Heart J. 2016 Mar;173:35-40. http://dx.doi.org/10.1016/j.ahj.2015.12.003 PMID:26920594

11. Auer R, Gencer B, Tango R, Nanchen D, Matter CM, Lüscher TF, et al. Uptake and efficacy of a systematic intensive smoking cessation intervention using motivational interviewing for smokers hospitalised for an acute coronary syndrome: a multicentre before-after study with parallel group comparisons. BMJ Open. 2016 Sep 20;6(9):eo11520. http://dx.doi.org/10.1136/bmjopen-2016-011520 PMID:27650761

12. Cordero A, Bertomeu-Martínez V, Mazón P, Cosín J, Galve E, Lekuona I, et al. Attitude and efficacy of cardiologists with respect to smoking in patients after acute coronary syndromes. Rev Espanola Cardiol Engl Ed. 2012 Aug;65(8):719-25. http://dx.doi. org/10.1016/j.recesp.2012.03.012 PMID:22739551 
13. Sriha Belguith A, Bouanene I, Elmhamdi S, Ben Salah A, Harizi C, Ben Salem K, et al. [Nicotine dependance and carbon monoxide intoxication among adult smokers]. Tunis Med. 2015 Apr;93(4):231-6 (in French). PMID:26375740

14. El Mhamdi S, Sriha A, Bouanene I, Ben Salah A, Ben Salem K, Soltani MS. Predictors of smoking relapse in a cohort of adolescents and young adults in Monastir (Tunisia). Tob Induc Dis. 2013 May 25;11(1):12. http://dx.doi.org/10.1186/1617-9625-11-12 PMID:23705806

15. Mills EJ, Wu P, Lockhart I, Wilson K, Ebbert JO. Adverse events associated with nicotine replacement therapy (NRT) for smoking cessation. A systematic review and meta-analysis of one hundred and twenty studies involving 177,390 individuals. Tob Induc Dis. 2010 Jul 13;8:8. http://dx.doi.org/10.1186/1617-9625-8-8 PMID:20626883

16. Woolf KJ, Zabad MN, Post JM, McNitt S, Williams GC, Bisognano JD. Effect of nicotine replacement therapy on cardiovascular outcomes after acute coronary syndromes. Am J Cardiol. 2012 Oct 1;110(7):968-70. http://dx.doi.org/10.1016/j.amjcard.2012.05.028 PMID:22727182

17. Eisenberg MJ, Windle SB, Roy N, Old W, Grondin FR, Bata I, et al. Varenicline for Smoking Cessation in Hospitalized Patients With Acute Coronary Syndrome. Circulation. 2016 Jan 5;133(1):21-30. http://dx.doi.org/10.1161/CIRCULATIONAHA.115.019634 PMID:26553744

18. Baha M, Le Faou A-L. [Proactive bedside counseling of smokers hospitalized in cardiac intensive care unit]. Ann Cardiol Angeiol (Paris). 2011 Aug;60(4):189-96 (in French). http://dx.doi.org/10.1016/j.ancard.2011.05.006 PMID:21722875

19. Kim H-E, Song Y-M, Kim B-K, Park Y-S, Kim M-H. Factors associated with persistent smoking after the diagnosis of cardiovascular disease. Korean J Fam Med. 2013 May;34(3):160-8. http://dx.doi.org/10.4082/kjfm.2013.34.3.160 PMID:23730483

20. 20. Smith PM, Burgess E. Smoking cessation initiated during hospital stay for patients with coronary artery disease: a randomized controlled trial. CMAJ Can Med Assoc J J Assoc Medicale Can. 2009 Jun 23;180(13):1297-303. http://dx.doi.org/10.1503/ cmaj.080862 PMID:19546455

21. Planer D, Lev I, Elitzur Y, Sharon N, Ouzan E, Pugatsch T, et al. Bupropion for smoking cessation in patients with acute coronary syndrome. Arch Intern Med. 2011 Jun 27;171(12):1055-6o. http://dx.doi.org/10.1001/archinternmed.2011.72 PMID:21403011

22. Prochaska JO, DiClemente CC. Stages and processes of self-change of smoking: toward an integrative model of change. J Consult Clin Psychol. 1983 Jun;51(3):390-5. PMID:6863699

23. Rigotti NA, Thorndike AN, Regan S, McKool K, Pasternak RC, Chang Y, et al. Bupropion for smokers hospitalized with acute cardiovascular disease. Am J Med. 2006 Dec;119(12):1080-7. http://dx.doi.org/10.1016/j.amjmed.2006.04.024 PMID:17145253

24. Rigotti NA, McKool KM, Shiffman S. Predictors of smoking cessation after coronary artery bypass graft surgery. Results of a randomized trial with 5-year follow-up. Ann Intern Med. 1994 Feb 15;120(4):287-93. PMID:8291821

25. Quist-Paulsen P, Bakke PS, Gallefoss F. Predictors of smoking cessation in patients admitted for acute coronary heart disease. Eur J Cardiovasc Prev Rehabil. 2005 Oct;12(5):472-7. http://dx.doi.org/10.1097/01.hjr.0000183914.90236.01 PMID:16210934

26. Joseph AM, Fu SS. Safety issues in pharmacotherapy for smoking in patients with cardiovascular disease. Prog Cardiovasc Dis. 2003 May-Jun;45(6):429-41. http://dx.doi.org/10.1053/pcad.2003.YPCAD14 PMID:12800126

27. Meine TJ, Patel MR, Washam JB, Pappas PA, Jollis JG. Safety and effectiveness of transdermal nicotine patch in smokers admitted with acute coronary syndromes. Am J Cardiol. 2005 Apr 15;95(8):976-8. http://dx.doi.org/10.1016/j.amjcard.2004.12.039 PMID:15820167

28. Stead LF, Lancaster T. Combined pharmacotherapy and behavioural interventions for smoking cessation. Cochrane Database Syst Rev. 2012 Oct 17;10:CDo08286. http://dx.doi.org/10.1002/14651858.CDoo8286.pub3 PMID:23076944

29. Cardiologists should be less passive about smoking cessation. Lancet Lond Engl. 2009 Mar 14;373(9667):867. http://dx.doi. org/10.1016/So140-6736(09)60518-3 PMID:19286063

30. Vogiatzis I, Tsikrika E, Sachpekidis V, Pittas S, Kotsani A. Factors affecting smoking resumption after acute coronary syndromes. Hellenic J Cardiol. 2010 Jul-Aug;51(4):294-300. PMID:20650827

31. Dornelas EA, Sampson RA, Gray JF, Waters D, Thompson PD. A randomized controlled trial of smoking cessation counseling after myocardial infarction. Prev Med. 2000 Apr;30(4):261-8. PMID:10731452

32. Perk J, De Backer G, Gohlke H, Graham I, Reiner Ž, Verschuren M, et al. European Guidelines on cardiovascular disease prevention in clinical practice (version 2012)The Fifth Joint Task Force of the European Society of Cardiology and Other Societies on Cardiovascular Disease Prevention in Clinical Practice (constituted by representatives of nine societies and by invited experts) Developed with the special contribution of the European Association for Cardiovascular Prevention \& Rehabilitation (EACPR). Eur Heart J. 2012 Jul;33(13):1635-701. http://dx.doi.org/10.1093/eurheartj/ehso92 PMID:22555213

33. Kim H-E, Song Y-M, Kim B-K, Park Y-S, Kim M-H. Factors Associated with Persistent Smoking after the Diagnosis of Cardiovascular Disease. Korean J Fam Med. 2013 May;34(3):160-8. http://dx.doi.org/10.4082/kjfm.2013.34.3.160 PMID:23730483

34. Perez GH, Nicolau JC, Romano BW, Laranjeira R. Depression: a predictor of smoking relapse in a 6-month follow-up after hospitalization for acute coronary syndrome. Eur J Cardiovasc Prev Rehabil Off J Eur Soc Cardiol Work Groups Epidemiol Prev Card Rehabil Exerc Physiol. 2008 Feb;15(1):89-94. http://dx.doi.org/10.1097/HJR.obo13e3282f4b212 PMID:18277192

35. Rocha V, Guerra M, Lemos M, Maciel J, Williams G. Motivation to quit smoking after acute coronary syndrome. Acta Med Port. 2017 Jan 31;30(1):34-40. http://dx.doi.org/10.20344/amp.7926 PMID:28501035 